\title{
Transesterification of Soybean Oil with Ethanol Using Heterogeneous Catalysts Based on Hydrotalcites
}

\author{
Evelyn Alves Nunes Simonetti ${ }^{1} \&$ Gilberto Garcia Cortez ${ }^{1}$ \\ ${ }^{1}$ Escola de Engenharia de Lorena, University of São Paulo, Lorena, São Paulo, Brazil \\ Correspondence: Evelyn Alves Nunes Simonetti, Escola de Engenharia de Lorena, University of São Paulo, \\ Lorena, São Paulo. E-mail: evelyn@dequi.eel.usp.br
}

Received: December 6, 2012 Accepted: January 16, 2013 Online Published: January 29, 2013

doi:10.5539/eer.v3n1p63 URL: http://dx.doi.org/10.5539/eer.v3n1p63

\begin{abstract}
This work evaluated the potential of hydrotalcites based in $\mathrm{Ca}-\mathrm{Al}$ on trasesterification of soybean oil with ethanol. The reaction was carried out at $78.5^{\circ} \mathrm{C}$ with ethanol:oil molar ratio of 30 and $10 \mathrm{wt} \%$ of catalyst. The $2 \mathrm{Ca}-\mathrm{Al}$ showed better performance than $3 \mathrm{Ca}-\mathrm{Al}$ catalyst achieving conversion of $94 \%$. The catalyst were characterized with XRD, BET and activity was evaluated on isopropanol decomposition reaction.
\end{abstract}

Keywords: biodiesel, ethanol, transesterification, hydrotalcite, soybean oil

\section{Introduction}

The search for renewable sources has opened a new field to fuels development and the biodiesel has stood out due to it same properties of convectional diesel and for the facility of being used directly in diesel engines or in mixtures. These properties are possible by the presence of mono-alkyl esters of long chain fatty acids on biodiesel structure. Another important fact is the biodiesel combustion, it has low emission of harmful gas such as sulfur oxide which is a great advantage to the environmental system (Gerogogianni et al., 2009; Helwani et al., 2009). Transesterification is the cheaper and easy route of biodiesel synthesis and it consists in a reaction between vegetable oil or animal fat with alcohol (methanol or ethanol) to form ester and glycerol. The stoichiometry is 3:1 (alcohol: triglycerides) and it is common to use an excess of alcohol to improve the yield (Enweremadu \& Mbarawa, 2009). Transesterification is often applied as a homogeneous reaction using acid and basic catalysts, such as sulfuric and hydrochloric acids, $\mathrm{KOH}$ and $\mathrm{NaOH}$ (Meher et al., 2006; Demirbas, 2009). The advantages of these catalysts are low reaction time and high yields. Although there are many disadvantages such formation of soup, elevated ratio alcohol:oil, impossibility of reuse the catalyst and difficulty in separating the catalyst from the azeotropic system. To avoid these problems countless studies have been published to develop new heterogeneous catalysts - such like metal hydroxides, oxides, zeolites, supported catalysts and hydrotalcites (Lee \& Saka, 2010; Semwal et al., 2011). Among these catalysts the hydrotalcites (LDHs) has opened a new source in heterogeneous catalysis due it innumerous composition and applications. The layered double hydroxides or hydrotalcites (LDHs) can be represented by the following general formula: $\left[\mathrm{M}_{1-x}{ }^{2+} \mathrm{M}_{x}^{3+}(\mathrm{OH})_{2}\right]^{x+} A^{m-}{ }_{x / m} n H_{2} \mathrm{O}$. The structure of hydrotalcites is based upon layered double hydroxides with brucite like $\left(\mathrm{Mg}(\mathrm{OH})_{2}\right)$ hydroxide layers containing octahedrally coordinated $\mathrm{M}^{2+}$ and $\mathrm{M}^{3+}$ cations (Crepaldi \& Valim, 1998). The thermal processing of HDL promotes the formation of metastable crystalline phases, such as the spinel phase and/or mixed oxides, forming acid and/or basic sites (Vaccari, 1998; Goh \& Lim, 2008). Studies developed identified four different types of active sites identified in calcined HDL samples: isolated $\mathrm{O}^{2-}$ ions, pairs of $\mathrm{Mg}^{2+} \mathrm{O}^{2-}$ and $\mathrm{OH}^{-}$groups and acid sites $\left(\mathrm{Al}^{3+}\right)$ (Di Cosimo et al., 1998). Many researches have been done on transesterification catalyzed by LDH. The most common hydrotalcite applied is the Mg-Al using methanol and vegetable oil as triglyceride source. It was achieved yields between 67-90.5\% (Siano et al., 2006; Xie et al., 2006; Zeng et al., 2008). Another types of hydrotalcite can be used on transesterifcation such like MgCoAl-LDH. In this particular study was used canola oil and ethanol, the results showed elevated yields at high ethanol:oil ratio (Li et al., 2009).

The objective of this study is to evaluate the catalytic performance of hydrotalcite in the transesterification reaction using $\mathrm{Ca}-\mathrm{Al}$ hydrotalcite obtained by continuous precipitation. It was evaluated the catalytic activity of the compounds with different molar ratio of $\mathrm{Ca} / \mathrm{Al}$. 


\section{Materials and Methods}

\subsection{Catalysis Synthesis}

The hydrotalcite precursors were prepared from aqueous solutions containing $\mathrm{Ca}\left(\mathrm{NO}_{3}\right)_{2} \cdot 6 \mathrm{H}_{2} \mathrm{O}$ and $\mathrm{Al}\left(\mathrm{NO}_{3}\right)_{3} \cdot 9 \mathrm{H}_{2} \mathrm{O}$. The atomic ratio, $\mathrm{y}=\mathrm{Ca}^{2+} / \mathrm{Al}^{3+}$, was equal to 2 and 3 . An aqueous solution of $1.5 \mathrm{~mol} / \mathrm{L}$ of $\mathrm{K}_{2} \mathrm{CO}_{3}$ was used as precipitating agent. These two solutions were maintained at $55{ }^{\circ} \mathrm{C}$ and mixed in a reactor keeping $\mathrm{pH}$ of $10.0 \pm 0.4$ during all process. The precipitate was kept at $40{ }^{\circ} \mathrm{C}$ for 24 hours under slow agitation. Then, it was separated by vacuum filtration and washed with deionized water up to neutral $\mathrm{pH}$. The catalysts were calcined at $450^{\circ} \mathrm{C}$ and named as $2 \mathrm{Ca}-\mathrm{Al}$ calcined and $3 \mathrm{Ca}-\mathrm{Al}$ calcined.

\subsection{Surface Area and Pore Volume}

Samples were treated at $300{ }^{\circ} \mathrm{C}$ for 3 hours in order to remove chemicals adsorbed. The surface area and pore volume were analyzed in an equipment BET, model Belsorp II, using nitrogen adsorption at $196{ }^{\circ} \mathrm{C}$ and relative pressures $\left(\mathrm{P} / \mathrm{P}_{0}\right)$ ranging from 0.05 to 0.35 . The pore distribution was determined using the $\mathrm{BJH}$ method from the adsorption/desorption isotherms and the specific area by BET method.

\section{$2.3 X$-ray Diffraction $(X R D)$}

X-ray diffraction were performed using the powder method an SEISERT equipment, model 1001, radiation $\mathrm{CuK \alpha}(\lambda=1.54178 \AA)$ and nickel filter. Crystalline phases were identified using JCPDS (Joint Committee of Powder Diffraction Standards, 1983).

\subsection{Isopropanol Decomposition Reaction}

The catalytic performance was evaluated through the decomposition of isopropanol, using a fixed bed reactor (quartz), with a continuous flow of reagents at atmospheric pressure. The activation of the catalyst was performed in situ at $200{ }^{\circ} \mathrm{C}$ for $2 \mathrm{~h}$ at oxygen (AGA, 99.9999\%) atmosphere. The reactor was fed with isopropanol (99.7\%, Merck) using a pump Thermo Separation Products, Model Spectra P100, at $0.05 \mathrm{~mL}$ of flow, diluted in a mixture of $\mathrm{He}$ and $\mathrm{O}_{2}$ (molar ratio 3/1) at a flow rate of $74 \mathrm{~mL} \cdot \mathrm{min}^{-1}$. The reaction was carried out at a range of $170{ }^{\circ} \mathrm{C}$ to $310{ }^{\circ} \mathrm{C}$, using catalyst mass of $100 \mathrm{mg}$ and a residence time factor $\left(\mathrm{W} / \mathrm{F}_{\mathrm{A} 0}\right)$ equal to 2.4

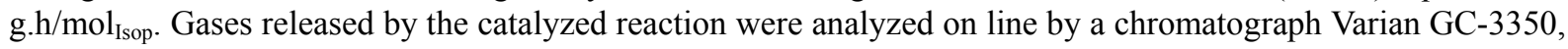
equipped with a thermal conductivity detector (TCD) and provided with a column packed Carbowax 20M, operating with a heating temperature between 30 and $150{ }^{\circ} \mathrm{C}$. Helium was used as carrier gas in the column.

The conversion $\left(X_{A}\right)$, selectivity $\left(\mathrm{S}_{\mathrm{p}}\right)$ and specific activity (mols of converted products) were calculated using Equations 1-3 and they were based on the input and output concentration and assuming a differential reactor:

$$
\begin{gathered}
X_{A}(\%)=\left(\frac{n I}{n I o}\right) 100 \\
\mathrm{Sp}(\%)=\left(\frac{\mathrm{np}}{\mathrm{nI}}\right)\left(\frac{\mathrm{NCP}}{\mathrm{NCI}_{\mathrm{CI}}}\right) 100 \\
\text { SpecificActivity }=\frac{\text { FAoXASp }}{\mathrm{W}_{\mathrm{ASg}}}
\end{gathered}
$$

Where:

$\mathrm{n}_{\mathrm{I}}$ : mols of isopropanol consumed;

$\mathrm{n}_{\mathrm{Io}}$ : mols of isopropanol fed;

$\mathrm{N}_{\mathrm{CP}}$ : mols of carbon atoms formed;

$\mathrm{N}_{\mathrm{CI}}$ : mols of carbon atoms in isopropanol;

$\mathrm{F}_{\mathrm{Ao}}$ : mols of isopropanol fed per minute;

$\mathrm{W}_{\mathrm{A}}$ : catalyst mass;

$\mathrm{S}_{\mathrm{g}}$ : catalyst specific area $\left(\mathrm{m}^{2} / \mathrm{g}\right)$.

\subsection{Transesterification with Ethanol}

The catalysts were activated in an oven at $200{ }^{\circ} \mathrm{C}$ for $24 \mathrm{~h}$ and the transesterification reactions were conducted in a spherical reactor $(500 \mathrm{~mL})$ equipped with a mechanical stirring. The amount of catalyst used in each experiment was $10 \%$ relative in mass of soybean oil. The experiments were performed in fixed conditions of temperature $\left(78.5^{\circ} \mathrm{C}\right.$ ) and molar ratio of 1 to 30 (oil/alcohol). In many works it is common to use a molar ratio up to 15:1 (alcohol:oil). Although, this proportion is more usually in reactions with methanol. In this work we 
use ethanol as alcohol font which is less reactive than methanol, so it was required a higher molar ratio. After the reaction the catalyst was separated by vacuum filtration. Then, distilled water was added to filtrate and homogenate. The upper phase was separated and washed twice with distilled water. Then, the sample was centrifuged and trace of methanol and ethanol were removed by distillation. The biodiesel was finally dried with anhydrous sodium sulfate and stored at $4{ }^{\circ} \mathrm{C}$ for further analysis.

2.6 Proton Nuclear Magnetic Resonance ( ${ }^{1} H$ NMR)

The biodiesel samples were diluted in deuterated chloroform ( $\mathrm{CDCl} 3$, Aldrich) and analyzed in a spectrometer model Varian MERCURY $300 \mathrm{MHz}$ operating in the region from 4.4 to $4.0 \mathrm{ppm}$. The absorption signals of chloroform were used as internal reference for the standard scale. The values of chemical shifts are expressed in units (ppm), coupling constants $(\mathrm{J})$ and $\operatorname{Hertz}(\mathrm{Hz})$.

The conversion in ethyl ester was evaluated based on the signals present in the region of 4.05 to $4.35 \mathrm{ppm}$ of ${ }^{1} \mathrm{H}$ NMR spectrum. In the ${ }^{1} \mathrm{H}$ NMR spectrum of soybean oil, this region represents the methylene hydrogens of triglyceril (Garcia, 2006). According to Equation 4 the resonance peak of the etoxyl hydrogen atoms of the ethyl esters split into a quartet. The area under the first and fourth peak is $A_{t} / 8$ and that one under the second and third is $3 A_{t} / 8$, where $A_{t}$ is the sum of areas under the four peaks. The fourth component $\left(\mathrm{A}_{c 4}\right)$ of the quartet of ethyl esters (range 4.07 to $4.08 \mathrm{ppm}$ ) is a single peak that does not suffer overlap from any other peak, so that component was used to calculate the conversion of ethanolysis vegetable oils.

$$
E E(\%)=\left(\frac{8 A_{c 4}}{A_{d d+e e}}\right) 100
$$

Where:

$\mathrm{A}_{c 4}=$ area of the component fourth peak;

$\mathrm{A}_{d d+e e}=$ area of all signals between 4.35 and $4.05 \mathrm{ppm}$;

$\mathrm{EE}(\%)=$ percentage of ethyl esters in vegetable oils.

\section{Results and Discussion}

\subsection{X-ray Diffraction (XRD)}

Figure 1 shows the $\mathrm{X}$-ray diffraction (XRD) profiles of the $2 \mathrm{Ca}-\mathrm{Al}$ not calcined, $2 \mathrm{Ca}-\mathrm{Al}$ calcined, $3 \mathrm{Ca}-\mathrm{Al}$ not calcined and $3 \mathrm{Ca}-\mathrm{Al}$ calcined samples. It can be observed that the samples $2 \mathrm{Ca}-\mathrm{Al}$ not calcined and $3 \mathrm{Ca}-\mathrm{Al}$ not calcined showed small peaks at $15^{\circ}, 18^{\circ}, 20^{\circ}, 23^{\circ}$ which are associated to layered structure. These peaks exhibit low intensity when compared to the conventional hydrotalcite $\mathrm{Mg}$-Al. There are also the peaks related to the formation of $\mathrm{CaCO}_{3}$ crystals (calcite) in $29^{\circ}, 47^{\circ}$ and $48^{\circ}$ (JCPDS 72-1652). After the calcination process the peaks related to layered structure disappear in $2 \mathrm{Ca}-\mathrm{Al}$ and $3 \mathrm{Ca}-\mathrm{Al}$ calcined samples. The elevated temperature of drying and calcination increases the rate of water and carbon dioxide released. This phenomenon damages the solid structure leading to a loss of the lamellar arrangement. Besides, the preparation method not ensure the uniform mixing of the $\mathrm{Ca}^{2+}$ and $\mathrm{Al}^{3+}$ and the $\mathrm{Ca}^{2+}$ cations can agglomerate, favoring the formation of $\mathrm{CaCO}_{3}$ crystals (Frost et al., 2009; Yu et al., 2011; Gao, 2010).

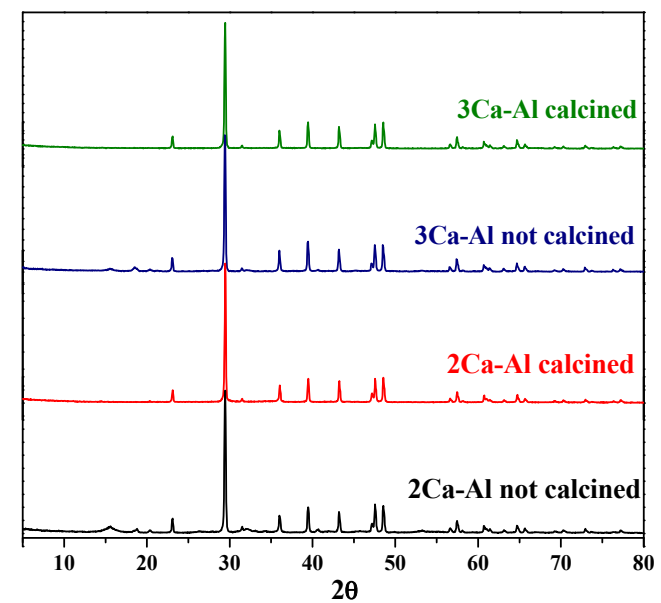

Figure 1. XRD patterns of samples $2 \mathrm{Ca}-\mathrm{Al}$ uncalcined, $3 \mathrm{Ca}-\mathrm{Al}$ uncalcined, $2 \mathrm{Ca}-\mathrm{Al}$ calcined at $450{ }^{\circ} \mathrm{C}$ and $3 \mathrm{Ca}-\mathrm{Al}$ calcined at $450{ }^{\circ} \mathrm{C}$ 


\subsection{Surface Area and Pore Volumes/Adsorption-Desorption}

Figure 2 shows the nitrogen adsorption/desorption isotherms measured at $-196{ }^{\circ} \mathrm{C}$ on $2 \mathrm{Ca}$-Al calcined and $3 \mathrm{Ca}-\mathrm{Al}$ calcined. Table 1 shows the characteristic parameters of the porosity of these catalysts, such as specific surface areas $\left(\mathrm{S}_{\mathrm{BET}}\right)$ and total pore volumes $\left(\mathrm{V}_{\mathrm{p}}\right)$. The isotherms can be classified as type III (IUPAC classification - International Union of Pure and Applied Chemistry). The shape of these isotherms is characteristic of non-porous or macroporous particles which interact very weakly with the adsorbent molecules. It also related to system with adsorption heat virtually nil and related to small gas volume - this can be observed in the sintered samples with surface area less than $5 \mathrm{~m}^{2} / \mathrm{g}$ (Sing et al., 1982; Santilli \& Pulcinelli, 1993). The hysteresis type is $\mathrm{H} 3$ and there are mainly two cases in which this type can be formed: very wide capillaries having narrow openings and an interstice between the parallel plates. It is also found in adsorption isotherms of many crystalline metal oxide aggregates of sheet-like shape. The slit width increase during adsorption and decreases irreversibly during desorption (Kaneko, 1994). Figure 2 also shows that the sample 2Ca-Al decreases the amount adsorbed as well the values of surface area and specific pore volume when compared to $3 \mathrm{Ca}-\mathrm{Al}$ as showed in Table 1. Despite the smaller specific surface area the sample 2Ca-Al has a larger average pore diameter in accordance with Table 1 . This may suggest that the $2 \mathrm{Ca}-\mathrm{Al}$ catalyst has pores wider than those in 3Ca-Al catalyst and also has a smaller number of pores (Teixeira et al., 2001).

Table 1. Values of specific surface area $\left(\mathrm{S}_{\mathrm{BET}}\right)$ and specific pore volume $\left(\mathrm{V}_{\mathrm{p}}\right)$ of the samples $2 \mathrm{Ca}-\mathrm{Al}$ calcined and $3 \mathrm{Ca}-\mathrm{Al}$ calcined

\begin{tabular}{cccc}
\hline Catalyst & $\mathrm{S}_{\mathrm{BET}}\left(\mathrm{m}^{2} / \mathrm{g}\right)(\mathrm{BET})$ & $\mathrm{V}_{\mathrm{p}}\left(\mathrm{cm}^{3} / \mathrm{g}\right)(\mathrm{BJH})$ & Pore Diameter $(\mathrm{nm})$ \\
\hline 2Ca-Al calcined & 6.60 & 0.07 & 45.10 \\
3Ca-Al calcined & 13.7 & 0.11 & 32.18 \\
\hline
\end{tabular}

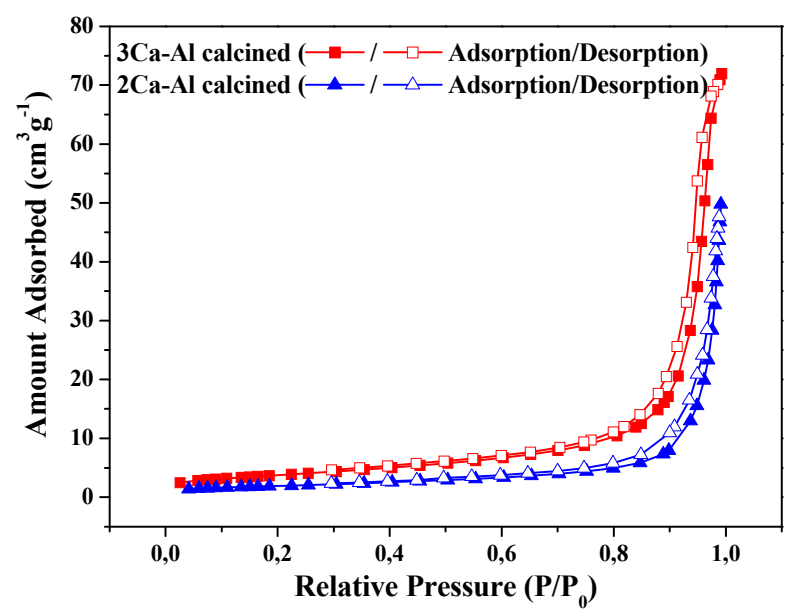

Figure 2. Nitrogen adsorption/desorption isotherms at $-196{ }^{\circ} \mathrm{C}$ of samples $2 \mathrm{Ca}-\mathrm{Al}$ calcined and $3 \mathrm{Ca}-\mathrm{Al}$ calcined

\subsection{Pore Size Distribution}

Figure 3 shows the pore size distribution (estimated by $\mathrm{N}_{2}$ adsorption) of the $2 \mathrm{Ca}-\mathrm{Al}$ calcined and $3 \mathrm{Ca}-\mathrm{Al}$ calcined catalysts. It can be note that the porous structure of $2 \mathrm{Ca}-\mathrm{Al}$ calcined and $3 \mathrm{Ca}-\mathrm{Al}$ calcined are basically composed of pore in the mesoporos region $(2 \mathrm{~nm}<w<50 \mathrm{~nm})$ with multimodal distribution indicating heterogeneity in the samples. In this region can be observed the presence of two peaks in about $10 \mathrm{~nm}$ for the $2 \mathrm{Ca}-\mathrm{Al}$ calcined and $50 \mathrm{~nm}$ for the $3 \mathrm{Ca}-\mathrm{Al}$ calcined sample. 


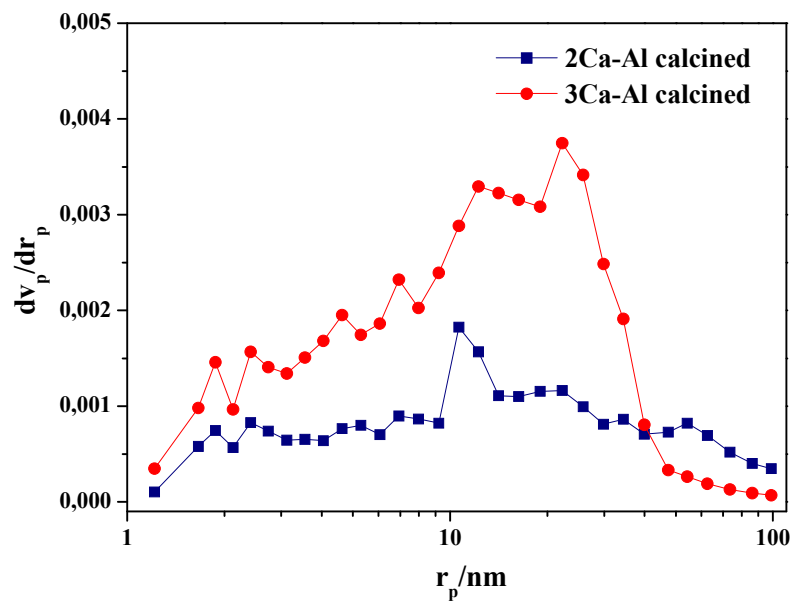

Figure 3. Pore size distribution of the samples $2 \mathrm{Ca}-\mathrm{Al}$ calcined and $3 \mathrm{Ca}-\mathrm{Al}$ calcined

\subsection{Isopropanol Decomposition Reaction}

Table 2 shows the results of specific catalytic activity of the catalysts evaluated in isopropanol decomposition reaction at $250{ }^{\circ} \mathrm{C}, 280{ }^{\circ} \mathrm{C}$ and $300^{\circ} \mathrm{C}$. The main products were propylene and diisopropyl ether in both catalysts. The $2 \mathrm{Ca}-\mathrm{Al}$ calcined sample showed higher specific catalytic activity at different temperatures when compared to the $3 \mathrm{Ca}-\mathrm{Al}$ calcined for both products, propylene and diisopropyl ether according to Table 2. Isopropanol conversion is often applied as catalytic test to obtain the effective catalytic properties of acid and base sites. Thus, the formation of propylene (from dehydration of isopropanol) or acetone (from dehydrogenation) provides information about the presence of acid and basic (or redox) centers, respectively (Gervasini et al., 1997). It can be observed that all samples showed the formation of propylene and diisopropyl ether. These products are related to dehydration of isopropanol using acid sites of the catalyst (Gervasini et al., 1997). The main reason to the acid sites are associated with great amount of aluminum ions represented to the high density of $\mathrm{Al}^{3+} \mathrm{O}^{2-}$ groups on the surface. However the basic groups are provides by $\mathrm{MgO}$ groups on the surface of the conventional hydrotalcites (Diez et al., 2003; Aramendia et al., 1996). The absence of basic represented by $\mathrm{Ca}^{2+} \mathrm{O}^{2-}$ groups is related to the bond between the calcium and carbonate. Both mechanism of propylene and diisopropyl formation are correlated to the abstraction of the alcohol molecule on catalysts surface by the acid site. This abstraction promotes the formation of cabanions and then olefins and ether (Robles-Medina et al., 2009). At $250{ }^{\circ} \mathrm{C}$ the diisopropyl formation was more intense with $3 \mathrm{Ca}-\mathrm{Al}$ catalyst however at $280^{\circ} \mathrm{C}$ and $300{ }^{\circ} \mathrm{C}$ the formation was much more intense with $2 \mathrm{Ca}-\mathrm{Al}$. The mechanism of ether and propylene formation can be represente below, were A represents an acid site and $\mathrm{B}$ a basic site.
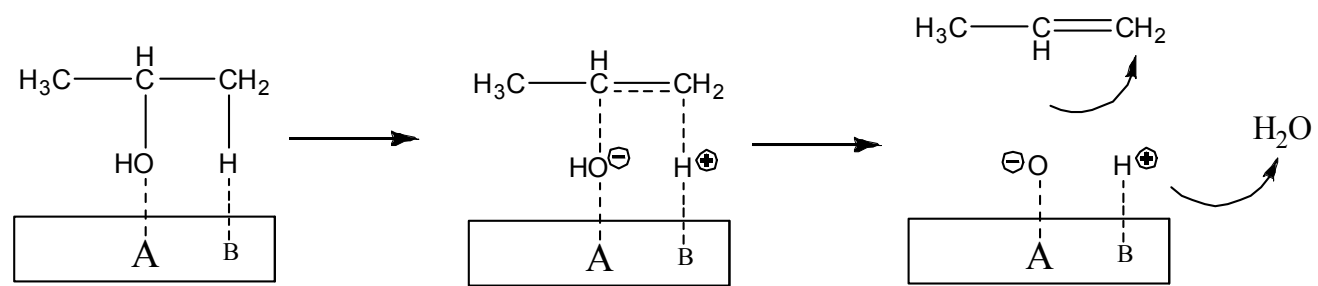

Figura 4. Mechanism of propylene formation on decomposition of isopropanol

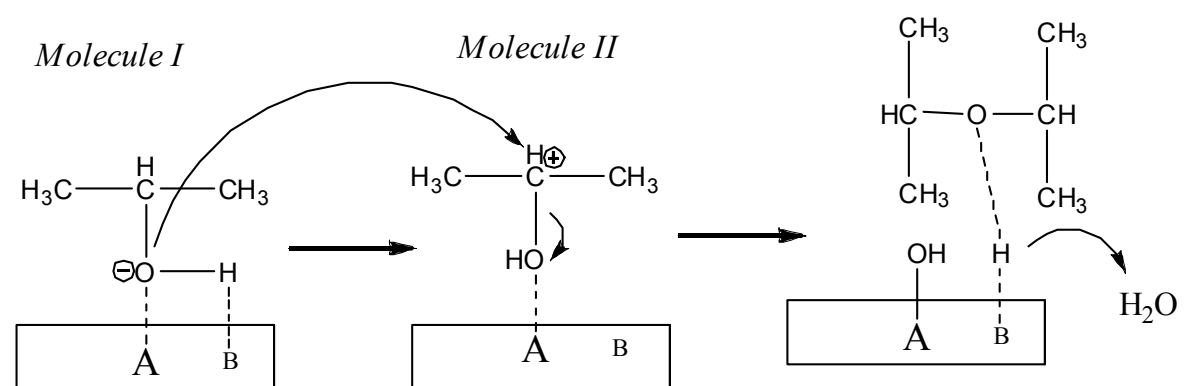

Figura 5. Mechanism of ether formation on decomposition of isopropanol 
Table 2. Specific catalytic activity of samples $2 \mathrm{Ca}-\mathrm{Al}$ calcined and $3 \mathrm{Ca}-\mathrm{Al}$ calcined

\begin{tabular}{ccccccc}
\hline \multirow{2}{*}{ Catalyst } & \multicolumn{5}{c}{ Specific Catalytic Activity $\left(10^{-4} \mathrm{~mol} \mathrm{~m}^{-2} \mathrm{~min}^{-1}\right)$} \\
\cline { 2 - 7 } & $250{ }^{\circ} \mathrm{C}$ & $280{ }^{\circ} \mathrm{C}$ & $300{ }^{\circ} \mathrm{C}$ & $250{ }^{\circ} \mathrm{C}$ & $280{ }^{\circ} \mathrm{C}$ & $300{ }^{\circ} \mathrm{C}$ \\
\cline { 2 - 7 } 2Ca-Al calcined & 0.110 & 0.440 & 1.400 & 0.002 & 0.140 & 0.660 \\
3Ca-Al calcined & 0.044 & 0.234 & 0.564 & 0.044 & 0.085 & 0.239 \\
\hline
\end{tabular}

\subsection{Transesterification Reaction}

${ }^{1} \mathrm{H}$ NMR technique was used to characterize and quantify the ethyl ester formation by the transesterification reaction of soybean oil. The technique used to evaluate the conversion of trilgycerides in ethyl esters is based on the signals presents in the region of 4.05 to $4.35 \mathrm{ppm}$ of ${ }^{1} \mathrm{H}$ NMR spectrum (Garcia, 2006). This region represents the methylene hydrogens of triglycerides molecules of soybean. After transesterification reaction the signals of etoxyl hydrogen of ester molecules takes place. The Figure 4 shows the spectra of the reactions catalyzed by $2 \mathrm{Ca}-\mathrm{Al}, 3 \mathrm{Ca}-\mathrm{Al}$ calcined and soybean oil. It can be observed that the transesterification catalyzed by $2 \mathrm{Ca}-\mathrm{Al}$ calcined showed the typical spectra etoxyl hydrogen of ethyl ester molecule. When compared with the soybean spectra it can be observed that there is no overlap with the signals of the triglyceride molecules indicating high conversion in ethyl esters. Table 3 shows the integration values of signals between 4.06 and 4.35 ppm where conversion with $2 \mathrm{Ca}-\mathrm{Al}$ calcined reached $94 \%$. The spectra of the reaction catalyzed by $3 \mathrm{Ca}-\mathrm{Al}$ calcined showed an overlap of signals between the methylene hydrogens of triglycerides and the signals of etoxyl hydrogen of ethyl ester molecule. It can be observed that the $3 \mathrm{Ca}$ - $\mathrm{Al}$ calcined spectra approaches to the soybean spectra indicating low conversion. The table 3 shows that the reaction catalyzed by $3 \mathrm{Ca}-\mathrm{Al}$ reached only $31 \%$ of conversion.

Table 3. Integration peaks and the conversion percentage determined by ${ }^{1} \mathrm{H}$ NMR

\begin{tabular}{cccc}
\hline Catalyst & Area $A_{c 4}$ & Area $\mathrm{A}_{d d+e e}$ & Conversion (\%) \\
\hline 2Ca-Al calcined & 1.06 & 7.58 & 94 \\
3Ca-Al calcined & 0.04 & 0.99 & 31 \\
\hline
\end{tabular}

The addition of calcium in the $3 \mathrm{Ca}-\mathrm{Al}$ catalyst was expected to enhance the conversion of ethanolysis due to the creation of basic sites which are more active than acid sites, but the effect was the opposite. The carbonate present in the samples displays no particular catalytic activity on the reaction. This function belongs to the mixed oxides after calcination (Xie et al., 2006). The $\mathrm{Al}^{3+}$ cations occupy the octahedral sites in hydrotalcites before calcination and the structure rearranges at high temperature in a tetrahedral form combined with $\mathrm{Ca}^{2+}$ cations. A positive charge is generated by this rearrangement and it is compensated by the formation of two types of defects: cationic vacancies and/or inclusion of intersticial oxygen which promotes the formation of sites like $\mathrm{Al}^{3+} \mathrm{O}^{2-}$ or $\mathrm{Ca}^{2+} \mathrm{O}^{2-}$ (Xie et al., 2006). In this study the main site formed was related to $\mathrm{Al}^{3+} \mathrm{O}^{2-}$ as evidenced in isopropanol decomposition reaction and the calcium content promotes the formation of carbonate. Adding more calcium in structure enhances the formation of carbonate and decreases the aluminum sites. With less active site available the access to the bulky triglyceride molecules decreases and then the conversion in ethyl esters is lower. Another important factor are the wider pores present in the $2 \mathrm{Ca}-\mathrm{Al}$ catalyst which provides more contact with the triglyceride molecules and then increase the conversion in ethyl esters. Despite the higher surface area of $3 \mathrm{Ca}-\mathrm{Al}$ catalysts it does not contributed to the elevation of conversion. The amount of carbonate formed occupies a large extension of catalyst inhibiting the action of the active sites and blocking contact with the triglyceride molecules. 


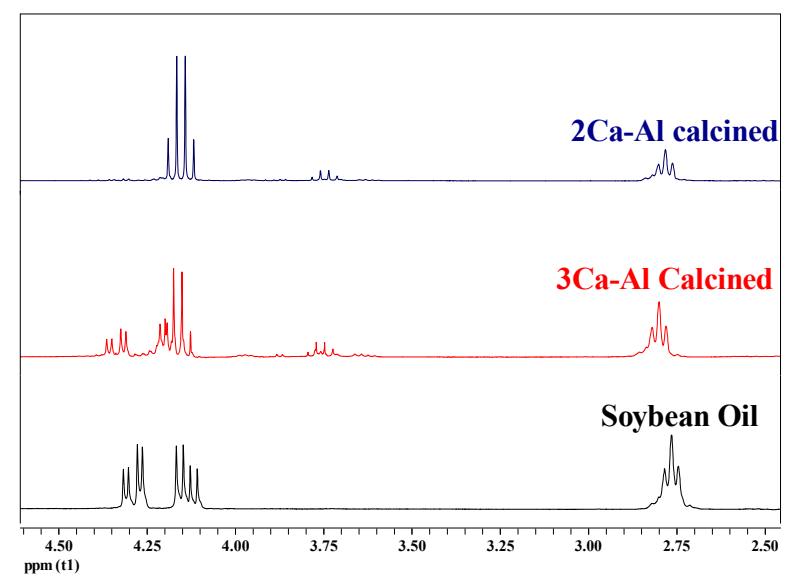

Figure $6 .{ }^{1} \mathrm{H}$ NMR spectra of soybean oil and ethyl ester catalyzed

\section{Conclusion}

In this work was proposed the use of heterogeneous catalysts using hydrotalcites in soybean oil ethanolysis. The $\mathrm{Ca}-\mathrm{Al} \mathrm{LDHs}$ were prepared by the co-precipitation method using $\mathrm{Ca} / \mathrm{Al}$ ratio of 2 and 3 . The XRD spectrum showed the appearance of peaks related to $\mathrm{CaCO}_{3}$ crystals in all samples - that can be the elevated temperature of drying and calcination used in this work. The isotherms were classified as type III characteristic of non-porous or macroporous particles which interact very weakly with the adsorbent molecules. The surface area of the catalyst increased with the addition of calcium content as also the pore volume. The $2 \mathrm{Ca}-\mathrm{Al}$ showed higher specific catalytic activity than $3 \mathrm{Ca}-\mathrm{Al}$. The acid sites formed were probably related to the aluminum content. The calcium addition inhibits these acid sites decreasing the production of propylene and ether in the isopropanol decomposition reaction. The transesterification of soybean oil reached the conversion of $94 \%$ with $2 \mathrm{Ca}-\mathrm{Al}$ catalyst and $31 \%$ with $3 \mathrm{Ca}-\mathrm{Al}$. The main reason for the difference in reaction yields is related to higher amount of active sites in the catalyst $2 \mathrm{Ca}-\mathrm{Al}$. The larger surface area of the catalyst $3 \mathrm{Ca}-\mathrm{Al}$ did not transform in higher yields.

\section{Acknowledgements}

The authors gratefully acknowledge the financial assistance to CAPES.

\section{References}

Aramendia, M. A., Borau, V., Jimenez, C., Marinas, J. M., Porras, A., \& Urbano, F. J. (1996). Magnesium Oxides as Basic Catalysts for Organic Processes: Study of the Dehydrogenation-Dehydration of 2-Propanol. $J$. Catal., 161, 829-838. http://dx.doi.org/10.1006/jcat.1996.0246

Crepaldi, E. L., \& Valim, J. B. (1998). Hidróxidos Duplos Lamelares: Síntese, Estrutura, Propriedades e Aplicações. Quim. Nova, 21, 300-311. http://dx.doi.org/10.1590/S0100-40421998000300011

Demirbas, A. (2009). Progress and recent trends in biodiesel fuels. Energ. Convers. Manage, 50, 14-34. http://dx.doi.org/10.1016/j.enconman.2008.09.001

Di Cosimo, J. I., Diez, V. K., Xu, M., Iglesia, E., \& Apesteguia, C. R. (1998). Structure and Surface and Catalytic Properties of Mg-Al Basic Oxides. J. Catal., 178, 499-510. http://dx.doi.org/10.1006/jcat.1998.2161

Díez, V. K., Apesteguía, C. R., \& Di Cosimo, J. I. (2003). Effect of the chemical composition on the catalytic performance of MgyAlOx catalysts for alcohol elimination reactions. J. Catal., 215, 220-223. http://dx.doi.org/ 10.1016/S0021-9517(03)00010-1

Enweremadu, C. C., \& Mbarawa, M. M. (2009). Technical aspects of production and analysis of biodiesel from used cooking oil-A review. Renew Sust. Energ. Rev., 13, 2205-2224. http://dx.doi.org/10.1016/j.rser.2009.06.007

Frost, R. L., Palmer, S. J., \& Spratt, H. J. (2009). Thermal decomposition of hydrotalcites with variable cationic ratios. J. Therm. Anal. Calorim., 95, 123-129. http://dx.doi.org/10.1007/s10973-008-8992-4

Gao, L., Teng, G., Xiao, G., \& Wei, R. (2010). Biodiesel from palm oil via loading KF/Ca-Al hydrotalcite catalyst. Biomass Bioenerg., 34, 1283-1288. http://dx.doi.org/10.1016/j.biombioe.2010.03.023 
Garcia, C. M. (2006). Vegetable oil transesterification. (M. S. Thesis). Universidade Estadual de Campinas, Campinas, SP.

Gerogogianni, K. G., Katsoulidis, A. P., Pomonos, P. J., \& Kontominas, M. G. (2009). Transesterification of soybean frying oil to biodiesel using heterogeneous catalysts. Fuel Process Technol., 90, 671-676. http://dx.doi.org/ 10.1016/j.fuproc.2008.12.004

Gervasini, A., Fenyvesi, J., \& Auroux, A. A. (1997). Study of the acidic character of modified metal oxide surfaces using the test of isopropanol decomposition. Catal Lett., 43, 219-228. http://dx.doi.org/10.1023/A:1018979731407

Goh, K. H., Lim, T. T., \& Dong, Z. (2008). Application of layered double hydroxides for removal of oxyanions: A review. Water Resour., 42, 1343-1368. http://dx.doi.org/ 10.1016/j.watres.2007.10.043

Helwani, Z., Othman, M. R., Azis, N., Fernando, W. J. N., \& Kim, J. (2009). Technologies for production of biodiesel focusing on green catalytic techniques: A review. Fuel Process Technol., 90, 1502-1514. http://dx.doi.org/10.1016/j.fuproc.2009.07.016

Joint Committee on Power Diffraction Standards. (1983). Powder Diffraction File. Swarthmore, PA International Center of Diffraction Data.

Kaneko, K. (1994). Determination of pore size and pore distribution 1. Adsorbent and catalysts. J. Membrane Sci., 96, 59-58. http://dx.doi.org/10.1016/0376-7388(94)00126-X

Lee, J. S., \& Saka, S. (2010). Biodiesel production by heterogeneous catalysts and supercritical technologies. Bioresourse Technol., 101, 7191-7200. http://dx.doi.org/10.1016/j.biortech.2010.04.071

Li, E., Xu, Z. P., \& Rudolph, V. (2009). MgCoAl-LDH derived heterogeneous catalysts for the ethanol transesterification of canola oil to biodiesel. Appl. Catal. B-Environ., 88, 42-49. http://dx.doi.org/10.1016/j.apcatb.2008.09.022

Meher, L. C., Vidya Sagar, D., \& Naik, S. N. (2006). Technical aspects of biodiesel production by transesterification-A review. Renew Sust. Energ. Rev., 10, 248-268. http://dx.doi.org/10.1016/j.rser.2004.09.002

Robles-Medina, A., González-Moreno, P. A., Esteban-Cerdán, L., \& Molina-Grima, E. (2009). Biocatalysis: Towards ever greener biodiesel production. Biotechnol. Adv., 27, 398-408. http://dx.doi.org/10.1016/j.biotechadv.2008.10.008

Santilli, C. V., \& Pulcinelli, S. H. (1993). Analise da Textura de Materiais Ceramicos A Partir das Isotermas de Adsorcao de Gases. Cerâmica, 39, 11-16.

Semwal, S., Arora, A. K., Badoni, R. P., \& Tuli, D. K. (2011). Biodiesel production using heterogeneous catalysts. Bioresourse Technol, 102, 2151-2161. http://dx.doi.org/10.1016/j.biortech.2010.10.080

Siano, D., Nastasi, M., Santacesaria, E., Di Serio, M., Tesser, R., Minutillo, G., .. Tenore, T. (2006). Process for producing esters from vegetable oils and animal fats by using heterogeneous catalysts. WO $050925 \mathrm{~A} 1$.

Sing, K. S. W., Everett, D. H., Haul, R. A. W., Moscou, L., Pierotti, R. A., Rouquérol, J., \& Siemieniewska, T. (1982). Reporting physisorption data for gas/solid systems with special reference to the determination of surface area and porosity. Pure Appl. Chem., 54, 2201-2218. http://dx.doi.org/10.1351/pac198254112201

Teixeira, V. G., Coutinho, F. M. B., \& Gomes, A. S. (2001). Principais Métodos de Caracterização da Porosidade de Resinas à base de Divinilbenzeno. Quim. Nova, 24, 808-818. http://dx.doi.org/10.1590/S0100-40422001000600019

Vaccari, A. (1998). Preparation and catalytic properties of cationic and anionic clays. Catal. Today, 41, 53-71. http://dx.doi.org/10.1016/S0920-5861(98)00038-8

Xie, W., Peng, H., \& Chen, L. (2006). Calcined Mg-Al hydrotalcites as solid base catalysts for methanolysis of soybean oil. J. Mol. Catal. A-Chem., 246, 24-32. http://dx.doi.org/10.1016/j.molcata.2005.10.008

Yu, C., Wang, C., Hsu, M., \& Chyou, Y. (2011). Development of a novel Ca/Al carbonates for medium-high temperature CO2 capture. Energy Procedia, 4, 787-794. http://dx.doi.org/10.1016/j.egypro.2011.01.120

Zeng, H. Y., Feng, Z., Deng, X., \& Li, Y. Q. (2008). Activation of Mg-Al hydrotalcite catalysts for transesterification of rape oil. Fuel, 87, 3071-3076. http://dx.doi.org/10.1016/j.fuel.2008.04.001 